\title{
Transcatheter Closure of Ruptured Sinus of Valsalva Aneurysm Report of two cases
}

"Khalfan S. Al-Senaidi, ${ }^{1}$ Abdullah Al-Farqani, ${ }^{2}$ Madan Maddali, ${ }^{3}$ Salim Al-Maskary ${ }^{2}$

$$
\text { إغلاق تمزق جيب فالسالفا الوعائي المتمدد بطريقة القسطرة التداخلية }
$$$$
\text { خلفان سالم السنيدي، عبداللة الفرقاني، مادان مادالي، سالم المسكري }
$$

ABSTRACT: A ruptured sinus of Valsalva aneurysm (RSVA) is a rare cardiac anomaly. Traditionally, RSVAs were repaired surgically; however, percutaneous transcatheter closure is the current treatment of choice. We report two cases of RSVA which were closed using this approach. The first case was a 45-year-old female who presented to the Royal Hospital, Muscat, Oman, in 2014 with a RSVA in the right ventricle. The second case was a 39-year-old male who was admitted to the Sultan Qaboos University Hospital, Muscat, in 2015 with a large multifenestrated RSVA extending into the right ventricle outflow tract. Each patient underwent transcutaneous cardiac catheterisation using three-dimensional echocardiography. Both interventions were technically successful; however, the second patient required a subsequent surgery due to the continuing presence of a significant shunt. Transcatheter closure of RSVAs is an effective alternative to surgical repair, although large multifenestrated RSVAs should be repaired surgically to ensure complete closure.

Keywords: Sinus of Valsalva; Ruptured Aneurysm; Cardiac Catheterization; Three-Dimensional Echocardiography; Case Report; Oman.

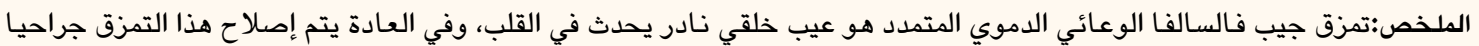

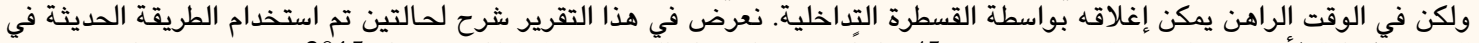

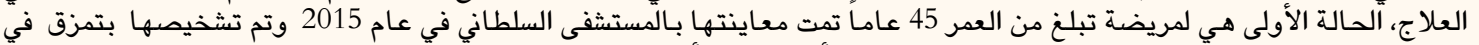

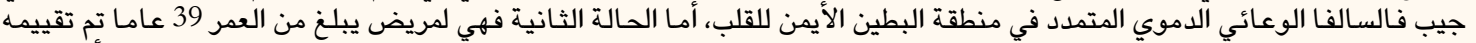

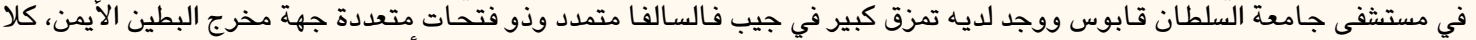

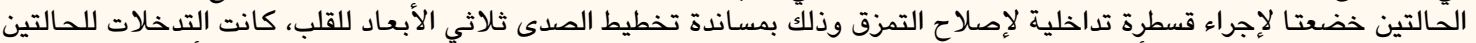

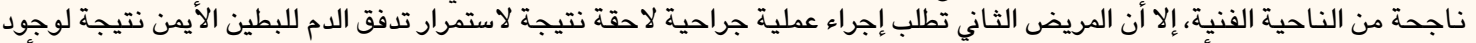

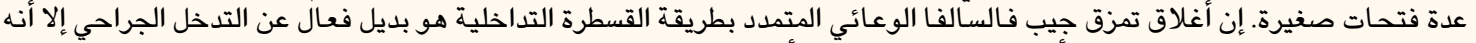

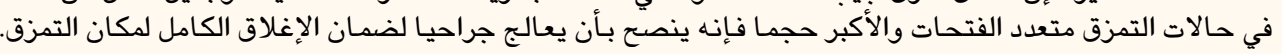
الكلمات المفتاحية: تمزق جيب فالسالفا، تمدد فالسالفا الوعائي، قسطرة قلبية، تخطيط القلب بالصدى ثلاثي الأبعاد، تقرير حالة، عمان.

$\mathrm{F}$ IRST DESCRIBED IN 1839, A RUPTURED SINUS of Valsalva aneurysm (RSVA) is a rare but wellknown clinical condition, with the rupture usually occurring in the right-sided cardiac chamber. ${ }^{1,2}$ These types of aneurysms are thin-walled saccular or tubular outpouchings of the aortic sinuses and can be either congenital or acquired. ${ }^{2}$ Echocardiography can accurately identify these lesions and confirm a diagnosis of RSVA. Cardiac surgical repair is the conventional method of treatment; however, trans-catheter closure has more recently been deemed the optimal choice of treatment. ${ }^{3}$ This report presents two cases of RSVA in which transcatheter closure was used. Complete closure of the defect was achieved in the first case. For the second case, which involved a patient with a multifenestrated aneurysmal defect, two devices were used during catheterisation. However, complete closure could not be achieved.

\section{Case 1}

A 45 year-old female with no known medical conditions presented to the Emergency Department of the Royal Hospital, Muscat, Oman, in 2014 with a one-day history of chest pain and shortness of breath. There was no history of fever. Her blood pressure was 120/55 $\mathrm{mmHg}$ and her heart rate was 85 beats per minute. A clinical examination revealed normal heart sounds, although a continuous murmur was audible over the third left intercostal space. An electrocardiogram and chest X-ray were normal with no features suggestive of a myocardial infarction. Her 

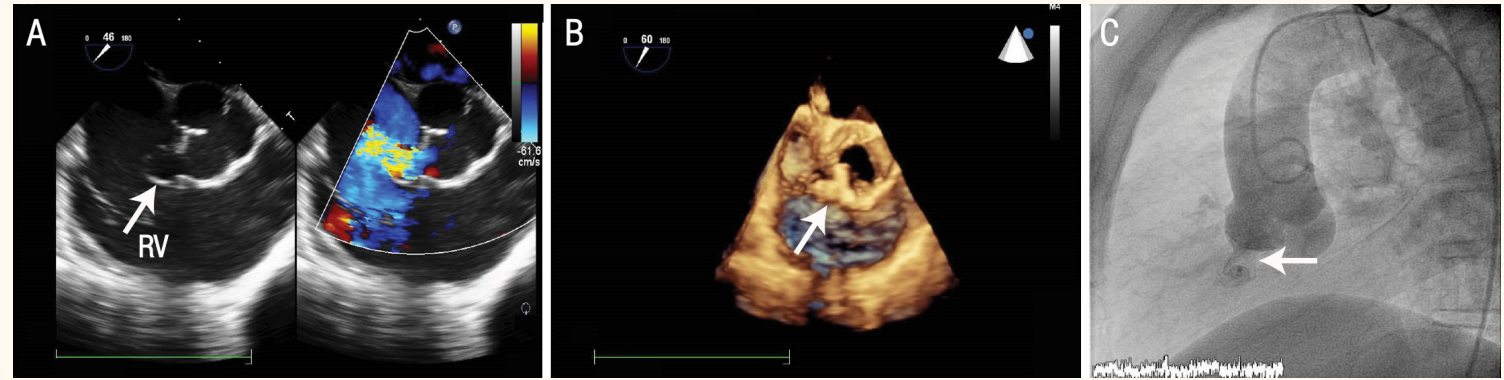

Figure 1: A: Two-dimensional transoesophageal echocardiography (TOE) in the short axis view showing a right sinus of Valsalva aneurysm (RSVA) extending into the right ventricle (arrow) of a 45-year-old female patient. B: Post-closure three-dimensional TOE in the short axis view showing the position of a cardiac catheter device (arrow) across the aneurysm. C: Post-closure lateral fluoroscopy showing the satisfactory position of the device (arrow), with no residual shunts or aortic valve regurgitation.

$R V=$ right ventricle.

troponin $\mathrm{T}$ levels were within the expected range ( $<5 \mathrm{pg} / \mathrm{mL})$. Transthoracic echocardiography (TTE) and transoesophageal echocardiography (TOE) revealed a RSVA extending from the right sinus into the right ventricle under the septal leaflet of the tricuspid valve. The aneurysm had a windsock appearance, with the aortic end measuring $10 \mathrm{~mm}$ and the opening into the right ventricle measuring $6 \mathrm{~mm}$ [Figure 1A] . She had a trileaflet aortic valve with no regurgitation. No ventricular septal defects, pericardial effusions or intracardiac vegetations were seen. The right and left ventricles were not dilated and demonstrated normal systolic function.

After discussion with cardiothoracic surgeons, a transcutaneous cardiac catheterisation intervention was performed. The patient was put under general anaesthesia, with the right femoral artery and vein punctured and a 6F short sheath secured. Unfractionated heparin and cefradine were administered intravenously at doses of $100 \mathrm{IU} / \mathrm{kg}$ and 1,000 mg, respectively. Two- and three-dimensional TOE scans confirmed the previous echocardiographic findings and haemodynamic data showed an increased left ventricular end-diastolic pressure of $15 \mathrm{mmHg}$ and a pulmonary to systemic blood flow (Qp:Qs) ratio of 3:1. An aortic root angiogram clearly delineated the RSVA, which was located far away from the right coronary artery with similar measurements to those observed via TOE. The RSVA was closed using a size 12/10 Cocoon Duct Occluder (Aeon World Group Corp., Taguig City, Manila, Philippines), which was inserted antegradely from the venous side. The RSVA was crossed from the aortic side with a $5 \mathrm{~F}$ Cordis $^{\mathrm{TM}}$ Judkins Right JR4 catheter (Cordis Corp., California, USA) using $0.89 \mathrm{~mm} \times 260 \mathrm{~cm}$ of guidewire (Terumo Interventional Systems, Terumo Medical Corp., Tokyo, Japan). An arteriovenous loop was established after the wire was snared from the left pulmonary artery. A 7F Mullins sheath (Cook Group, Bloomington,
Indiana, USA) was placed into the ascending aorta before the occluder was introduced; the skirt of the device was opened in the ascending aorta under fluoroscopic and TOE guidance. The device was pulled as one unit into the RSVA and the sheath retracted over the cable to deploy the rest of the device. Threedimensional TOE and an angiogram confirmed that the device was in a satisfactory position, with minimal flow through the device and no aortic valve regurgitation [Figures $1 \mathrm{~B}$ and $\mathrm{C}$ ].

The following day, TTE confirmed that the device was well-positioned, with total occlusion of the RSVA and no aortic or tricuspid valve regurgitation. The patient was discharged and prescribed a six-month course of aspirin ( $5 \mathrm{mg} / \mathrm{kg}$ per day) and a two-month course of clopidogrel (75 mg per day), with close follow-up.

\section{Case 2}

A 39-year-old man was admitted to the Sultan Qaboos University Hospital, Muscat, in 2015 with a two-month history of chest pain, shortness of breath and exercise intolerance. Clinically, he showed signs of aortic regurgitation, with an early diastolic murmur along the left sternal border. Using TTE, a RSVA extending into the right ventricular outflow tract (RVOT) was observed, with a dilated left ventricle. A mitral annulus $(5 \mathrm{~cm})$ and mild mitral and aortic valve regurgitation were also noted. The aneurysm had two large fenestrations of $8 \mathrm{~mm}$ in diameter each, in addition to multiple smaller defects. The mouth of the main aneurysm was $17 \mathrm{~mm}$ in diameter and the right coronary artery was in close proximity to the opening of the aneurysm. The aneurysm protruded into the RVOT but did not obstruct it.

The patient underwent transcutaneous cardiac catheterisation of the ruptured aneurysm under TOE guidance with on-site surgical back-up. A TOE scan 

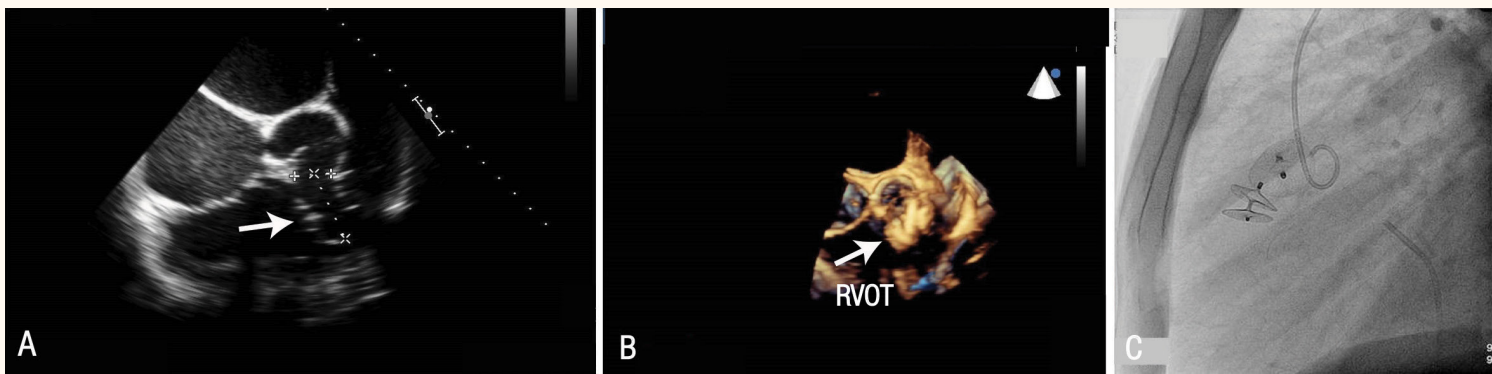

Figure 2: A: Two-dimensional transoesophageal echocardiography (TOE) in the short axis view showing a multifenestrated right sinus of Valsalva aneurysm (RSVA) into the right ventricular outflow tract (arrow) of a 39-year-old male patient. B: Post-closure three-dimensional TOE in the short axis view showing the position of two cardiac catheter devices (short arrow) across the aneurysm, with the right ventricular outflow tract wide open. C: Post-closure lateral fluoroscopy showing the position of the devices.

RVOT = right ventricular outflow tract.

confirmed the TTE findings and showed that the RSVA was $3.4 \mathrm{~cm}$ with a $17 \mathrm{~mm}$ mouth [Figure $2 \mathrm{~A}$ ]. The right femoral artery and vein as well as the left femoral artery were accessed using $8 \mathrm{~F}, 10 \mathrm{~F}$ and $6 \mathrm{~F}$ sheaths, respectively. The coronary arteries were normal and the Qp:Qs ratio was 5.2:1, with a pulmonary vascular resistance index of 1.6 Wood units. As previously described for the first patient, the fenestrated defect was crossed and an arteriovenous loop established. The first fenestration was closed with a $23 / 25 \mathrm{~mm}$ Occlutech $^{\circledR}$ Figulla $^{\circledR} \quad$ PFO Occluder (Occlutech $\mathrm{GmbH}$, Jena, Germany), inserted antegradely from the venous side. A large shunt in the second fenestration was identified via TOE, necessitating the use of a second device; hence, an $18 \mathrm{~mm}$ AMPLATZER ${ }^{\mathrm{TM}}$ PFO Occluder (St. Jude Medical Inc., St. Paul, Minnesota, USA) was deployed retrogradely from the arterial side. This device was deployed retrogradely in order to close the aneurysm from the RVOT towards the left ventricle and to secure the two devices in a more stable position. The right coronary artery was not affected by the devices and both devices were placed in suitable positions [Figures $2 \mathrm{~B}$ and $\mathrm{C}$ ]. Following the intervention, the Qp:Qs ratio decreased to 2.2:1 and TEE revealed mild aortic regurgitation.

The patient was discharged the following day, after a TTE scan confirmed the position of the devices. However, a mild-to-moderate shunt was present across the aneurysm, with no RVOT obstruction. The mild aortic regurgitation persisted. The patient was prescribed $75 \mathrm{mg}$ of aspirin daily for six months and $75 \mathrm{mg}$ of clopidogrel daily for two months. On followup, the patient reported significant improvement in his symptoms. Echocardiography confirmed that the two devices were still in a satisfactory position across the aneurysm with no RVOT obstruction; however, there was a significant shunt across the other small defects. The patient subsequently underwent successful surgical correction of the aneurysm a few months later.

\section{Discussion}

Congenital RSVAs account for $0.1-3.5 \%$ of congenital heart defects and have a higher incidence in Asian versus Western populations. ${ }^{3,4}$ These aneurysms usually rupture into the right side of the heart, producing a left-to-right shunt which has a profound haemodynamic effect. ${ }^{3}$ Drainage sites can be single or multiple, with the right ventricle being the most common. ${ }^{5}$ Previous research has described a wide spectrum of presentations, ranging from an asymptomatic murmur to cardiogenic shock or even sudden cardiac death. ${ }^{5}$ Lillehei et al. reported the first successful repair of RSVAs for three patients in 1957. 6 Traditionally, surgical closure has been the mainstay of treatment for RSVAs, with an operative mortality rate of $<5 \%$ and excellent long-term outcomes. ${ }^{4,7}$ Nevertheless, these patients remain at risk of prolonged hospital stays and postoperative complications such as chest pain and septicaemia, making percutaneous device closure an attractive alternative. ${ }^{4}$ The transcatheter closure of a RSVA was first reported by Cullen et al. in 1994 using a Rashkind umbrella device. ${ }^{8}$ Advances in cardiac catheterisation technology have resulted in a wide range of devices and coils which can be used to close a RSVA. ${ }^{9-15}$ Retrograde and combined minimally invasive surgery hybrid approaches have been described in certain cases. ${ }^{16,17}$

Based on a retrospective review of 257 patients, Guo et al. proposed a new system of simple surgical classification for right-sided defects according to rupture site. ${ }^{18}$ This classification system identifies four types of rupture: type I, a rupture or protrusion into the right atrium; type II, a rupture or protrusion into the right atrium or right ventricle, near or at the tricuspid annulus; type III, a rupture or protrusion into the right ventricular outflow tract, under the pulmonary valve; and type IV, other types of ruptures or protusions. ${ }^{18}$ Another system of angiographic classification uses the shape of the left-to-right shunt 
jet in order to facilitate the selection of occluders for percutaneous closure. ${ }^{19}$ The four types of shunt jets identified are: type I, window-like; type II, aneurysmal; type III, tubular; and type IV, other rare conditions. ${ }^{19}$ With regards to the current cases, the first patient had a type III shunt jet and the second patient had a type II shunt jet.

The current report describes two patients with RSVAs in which a transcatheter approach was used to close the aneurysms. In the first case, the RSVA was closed using an occluder made of platinumcoated nitinol wires. This is a self-expanding doubledisk device connected by a joint at the centre of the disks, which are filled with polypropylene fabric to increase thrombogenicity. Complete closure of the defect was achieved in this case. The second patient had a complex multifenestrated RSVA with two large defects and additional smaller defects. The RSVA penetrated into the RVOT and required two devices to close the larger defects. Initially, the interventionist intended to close the aneurysm at its entry point; however, due to the close proximity of the right coronary ostia to the mouth of the aneurysm, it was decided to close the RSVA at the exit point instead. Patent foramen ovale occluders were used as they have large retention discs on both sides which are nearly equal in size. As the aneurysm was multifenestrated, the devices were positioned in order to cover as many of the smaller defects as possible. Nevertheless, the patient continued to experience a significant shunt through the small defects and was referred for further surgical correction. These two cases demonstrate the two extremes of RSVA in terms of complexity. As observed with the second patient, large multifenestrated RSVAs should be closed surgically-if closure at the point of entry is not possible-in order to prevent the occurrence of smaller defects. In most cases of RSVA, the coronary ostia are quite high and device impingement occurs rarely. Ventricular septal defects often coexist with RSVAs, especially in patients with significant aortic valve regurgitation. ${ }^{20}$ Thankfully, neither patient in the current report had a ventricular septal defect.

\section{Conclusion}

Transcatheter closure is a safe and effective treatment option for patients with RSVAs. Real-time three-dimensional echocardiography allows easy visualisation of the defect and is helpful in guiding deployment of the device. However, surgical repair is recommended for large multifenestrated defects to prevent the development of further small defects after closure. The long-term follow-up of RSVA patients is mandatory to ensure complete closure of the aneurysm.

\section{References}

1. Perloff JK. The Clinical Recognition of Congenital Heart Disease, 5th ed. Philadelphia, Pennsylvania, USA: Saunders, 2003. Pp. 457-70.

2. Goldberg N, Krasnow N. Sinus of Valsalva aneurysms. Clin Cardiol 1990; 13:831-6. doi: 10.1002/clc.4960131204.

3. Chang CW, Chiu SN, Wu ET, Tsai SK, Wu MH, Wang JK. Transcatheter closure of a ruptured sinus of Valsalva aneurysm. Circ J 2006; 70:1043-7. doi: 10.1253/circj.70.1043.

4. Chu SH, Hung CR, How SS, Chang H, Wang SS, Tsai $\mathrm{CH}$, et al. Ruptured aneurysms of the sinus of Valsalva in Oriental patients. J Thorac Cardiovasc Surg 1990; 99:288-98.

5. Shah RP, Ding ZP, Ng AS, Quek SS. A ten-year review of ruptured sinus of Valsalva: Clinico-pathological and echoDoppler features. Singapore Med J 2001; 42:473-6.

6. Lillehei CW, Stanley P, Varco RL. Surgical treatment of ruptured aneurysms of the sinus of Valsalva. Ann Surg 1957; 146:459-72. doi: 10.1097/00000658-195709000-00014.

7. vanSonJA, Danielson GK, SchaffHV, OrszulakTA, Edwards WD, Seward JB. Long-term outcome of surgical repair of ruptured sinus of Valsalva aneurysm. Circulation 1994; 90:II20-9.

8. Cullen S, Somerville J, Redington A. Transcatheter closure of ruptured aneurysm of the sinus of Valsalva. Br Heart J 1994; 71:479-80. doi: 10.1136/hrt.71.5.479.

9. Rao PS, Bromberg BI, Jureidini SB, Fiore AC. Transcatheter occlusion of ruptured sinus of Valsalva aneurysm: Innovative use of available technology. Catheter Cardiovasc Interv 2003; 58:130-4. doi: $10.1002 / \mathrm{ccd} .10394$.

10. Tong S, Zhong L, Liu J, Yao Q, Guo Y, Shu M, et al. The immediate and follow-up results of transcatheter occlusion of the ruptured sinus of Valsalva aneurysm with duct occluder. J Invasive Cardiol 2014; 26:55-9.

11. Kerkar PG, Lanjewar CP, Mishra N, Nyayadhish P, Mammen I. Transcatheter closure of ruptured sinus of Valsalva aneurysm using the Amplatzer duct occluder: Immediate results and mid-term follow-up. Eur Heart J 2010; 31:2881-7. doi: 10.1093/ eurheartj/ehq323.

12. Bialkowski J, Akdeniz C, Celebi A. Transcatheter closure in two rare cases of left-to-right shunt with Cardio-O-Fix occluders. Cardiol Young 2012; 22:96-9. doi: 10.1017/S1047951 111000680.

13. Rittger H, Gundlach U, Koch A. Transcatheter closure of ruptured sinus of Valsalva aneurysm into the right ventricle with an Amplatzer Vascular Plug II. Catheter Cardiovasc Interv 2015; 85:166-9. doi: 10.1002/ccd.25382.

14. Altekin RE, Karakas MS, Er A, Yanikoglu A, Ozbek S, Yilmaz H. Percutaneous closure of ruptured sinus of Valsalva aneurysm with Amplatzer ductal occluder. Acta Cardiol 2011; 66:657-60. doi: 10.2143/AC.66.5.2131095.

15. Arora R, Trehan V, Rangasetty UM, Mukhopadhyay S, Thakur AK, Kalra GS. Transcatheter closure of ruptured sinus of Valsalva aneurysm. J Interv Cardiol 2004; 17:53-8. doi: 10.11 11/j.1540-8183.2004.01714.x

16. Jayaranganath $\mathrm{M}$, Subramanian A, Manjunath $\mathrm{CN}$. Retrograde approach for closure of ruptured sinus of Valsalva. J Invasive Cardiol 2010; 22:343-5. 
17. Cao X, Zhang F, Wang L, Jing H, Li N. Transthoracic minimally invasive closure for the treatment of ruptured sinus of Valsalva aneurysm: A case report. J Cardiothorac Surg 2014; 9:27. doi: 10.1186/1749-8090-9-27.

18. Guo HW, Xiong $\mathrm{H}, \mathrm{Xu}$ JP, Wang XQ, Hu SS. A new and simple classification for sinus of Valsalva aneurysms and the corresponding surgical procedure. Eur J Cardiothorac Surg 2013; 43:1188-93. doi: 10.1093/ejcts/ezs673.
19. Liu S, Xu X, Chen F, Zhao Z, Zhang Y, Wang C, et al. Angiographic features of ruptured sinus of Valsalva aneurysm: New classification. J Cardiol 2014; 64:139-44. doi: 10.1016/j. jjcc.2013.12.004.

20. Sakakibara S, Konno S. Congenital aneurysm of the sinus of Valsalva associated with ventricular septal defect: Anatomical aspects. Am Heart J 1968; 75:595-603. doi: 10.1016/00028703(68)90320-7. 